\title{
Corrosion Inhibition Behaviour for Mild Steel by Extracts of Musa sapientum Peels in HCl Solution: Kinetics and Thermodynamics Study
}

\author{
Olasehinde, E.F. ${ }^{1}$, Adesina, A. S. ${ }^{1}$, Fehintola, E. O. ${ }^{2}$, Badmus, B. M. ${ }^{1}$, \\ Aderibigbe, A. D. ${ }^{1}$ \\ ${ }^{1}$ (Department of Chemistry, Federal University of Technology, Akure, Nigeria) \\ ${ }^{2}$ (Department of Chemistry, Adeyemi College of Education, Ondo, Nigeria)
}

\begin{abstract}
The inhibition of the corrosion of mild steel by acid extract of Musa sapientum peels in $1 \mathrm{M} \mathrm{HCl}$ was investigated using weight loss method. The results showed that the corrosion rate of mild steel in $1 \mathrm{M} \mathrm{HCl}$ decreases with increase in concentration of the extracts and the values were in the range $0.013021-0.002127$ $\mathrm{ghr}^{-1} \mathrm{~cm}^{-2}$. The inhibition efficiency increases progressively as the concentration of the extracts increases up to about $4 \%(\mathrm{v} / \mathrm{v})$, above which, further increase in extract concentration did not cause any significant change in the inhibition efficiency. Effects of temperature on the inhibition efficiency of the extracts showed that inhibition efficiency decreases with increase in temperature. Activation energy (Ea) was found to be 61.60 $\mathrm{Kjmol}^{-1}$ for $1 \mathrm{M} \mathrm{HCl}$ and increases to $66.72 \mathrm{Kjmol}^{-1}$ in the presence of Musa sapientum extract. The values for enthalpy of activation and entropy were all positive indicating the endothermic nature of the mild steel dissolution process. Calculated Gibbs free energy was in the range -9.43 to $-8.99 \mathrm{KJ}$. Kinetics of the reaction in the presence of the extracts revealed that it follows a first order reaction and the half-life increases as the concentration of the extracts increases suggesting that inhibition efficiency increases with increase in the concentration of the extracts. Preliminary investigation of the phytochemical constituents showed that Musa sapientumcontains tannin, flavonoid, terpenoid and some other compounds in trace constituents.
\end{abstract}

Keywords-Steel corrosion, inhibitor, Musa sapientum, kinetics, and thermodynamics

\section{Introduction}

Considerable efforts are being deployed to find suitable compounds to be used as corrosion inhibitors in various corrosion media to prevent the metal form being attacked. Many metals and alloys which are used in different human activities are susceptible to different mechanisms of corrosion due to exposure to different corrosive media. The study of mild steel corrosion phenomena has become important particularly in acid media because of the increased industrial applications of acid solutions [1]. Acid solutions are commonly used for removal of undesirable scale and rust in metal finishing industries, cleaning of boilers, and heat exchangers. Among these, hydrochloric acid is one of most widely used agents in the process of acid pickling.

The use of inhibitors is one of the most practical methods for protection metals against corrosion especially in acid solutions to prevent unexpected metal dissolution and acid consumption [2]. Inorganic compounds like chromate, phosphates, molybdates etc. and the variety of organic compounds containing heteroatom like nitrogen, sulphur and oxygen are being investigated as corrosion inhibitors [3]. But, unfortunately most of these compounds are highly toxic to both human beings and environment being carcinogenic and mutagenic. Hence, the uses of natural products which are eco-friendly are being used as corrosion inhibitors. The development of corrosion inhibitors of natural source and non-toxic type has been considered more important and desirable [3], because they are renewable, economical, easy to extract and readily available.

Extracts of various plants have been investigated for use as green inhibitors such as Nyctanthesarbortristis[4], Nerium oleander andTecomastans[5], Indian Gooseberry [6] Kalmegh [7], Cola acuminate [8], Pipali and Brahmi [9], Cocoa leaves [10], Punicagranatum[11], Black pepper [12] and Uncariagambir [13]. In furtherance of this research, we have investigated the corrosion inhibition behaviour of the peels of Musa sapientumfriuts on mild steel in hydrochloric acid solutions with a view to understanding its kinetics and thermodynamics bahaviours.

\section{Experimental}

\subsection{Inhibitor Preparation}

The peels of Musa sapientum fruits were collected from the chips manufacturing shops in Akure, Nigeria. The peels were oven-dried at $95^{\circ} \mathrm{C}$, grounded and sieved through a mesh 850 micron. Stock solution of the plant extract was prepared by refluxing $10 \mathrm{~g}$ of the powdered material with $100 \mathrm{ml}$ of $1 \mathrm{M} \mathrm{HCl}$ for about 3 
hours and was allowed to stand overnight. The resultant solution was filtered and the filtrate was made up to 200 $\mathrm{mL}$. From the stock solution of the extract, different concentrations of the inhibitor test solutions ranging from $0.1 \%$ to $10 \% \mathrm{v} / \mathrm{v}$ were prepared. The blank corrodent was $1 \mathrm{M} \mathrm{HCl}$ solution and double distilled water was used for the entire study.

\subsection{Sample Preparation}

The chemical compositions of mild steel used were Fe: $98.721 \%, \mathrm{C}: 0.181 \%$, Si: $0.056 \%$, Mn: 0.474 $\%$, S: $0.039 \%$, Ni: $0.078 \%$, Cu: 0.198\%, Al: 0.124\%, P: 0.039\%, Cr: $0.038 \%$ and others were $0.091 \%$. The steel was cut to form different coupons of dimensions of diameter ranging from 5.35-5.67 mm and height ranging from 18.03-21.14 mm using digital venier caliper. Each coupon was degreased with acetone and pickled with concentrated hydrochloric acid. The surface of the coupons were mechanically polished using SiC emery papers of grades 400 and 600, washed with distilled water, dried at room temperature and stored in a desiccator. The weights of the coupons were determined using an analytical balance of $0.0001 \mathrm{mg}$ accuracy.

\subsection{Weight loss method}

After initial weighing, the specimens in triplicate were immersed in $100 \mathrm{ml}$ of $1 \mathrm{M} \mathrm{HCl}$ solution with and without different concentrations of plants extracts with the aid of glass hooks at different temperatures for 6 hours. The thermostated water bath was set to the appropriate temperature and after 6 hours of immersion, the specimens were removed, washed, dried completely and their final weights were noted. From the initial and final weights of the mild steel, the weight loss, the corrosion rate $\left(\mathrm{gcm}^{-2} \mathrm{hr}^{-1}\right)$, inhibition efficiency $(\%)$, and surface coverage $(\theta)$ were determined from the weight loss results, using equations 1, 2 and 3 respectively [13]:

$$
\text { Corrosion rate }(\mathrm{CR})={ }^{W} / \mathrm{At}\left(\mathrm{gcm}^{-2} \mathrm{~h}^{-1}\right)
$$

$\mathrm{W}$ is weight loss of the mild steel after time $\mathrm{t}$ (grams), " $\mathrm{A}$ " is the area of the mild steel coupon $\left(\mathrm{cm}^{2}\right)$ and " $\mathrm{t}$ " is the time of immersion (hours)

$$
\begin{aligned}
& \text { Inhibition efficiency }(\%)=\left(1-{ }^{W_{1}} / W_{2}\right) \times 100 \ldots \\
& \text { Surface Coverage }(\theta)=\left(1-{ }^{W_{1}} / W_{2}\right) \ldots \ldots \ldots \ldots \ldots
\end{aligned}
$$

Where $\mathrm{W}_{1}$ and $\mathrm{W}_{2}$ are the weight losses for mild steel in the presence and absence of inhibitor. Phytochemical analysis of the Musa sapientum extracts was carried out according to the method reported previously [14].

\section{Results And Discussion}

\subsection{Effect of Reaction Conditions on Corrosion Rate and Inhibition Efficiency of Musa Sapientum Extract} 3.1.1 Effect of concentration on corrosion rate

The variation of corrosion rate of mild steel in $1 \mathrm{M} \mathrm{HCl}$ in the absence and presence of various concentrations of acid extract of Musa sapientum at 303, 313, 323 and 333K was shown in Figure 1. The result showed that the corrosion rate of mild steel in $1 \mathrm{M} \mathrm{HCl}$ decreases with increase in the concentration of the extracts at all temperature vlaues, indicating that acid extracts of Musa sapientum inhibited the corrosion of mild steel in $1 \mathrm{M} \mathrm{HCl}$. This result was found to be in agreement with the findings of J.T Wabanne [13].
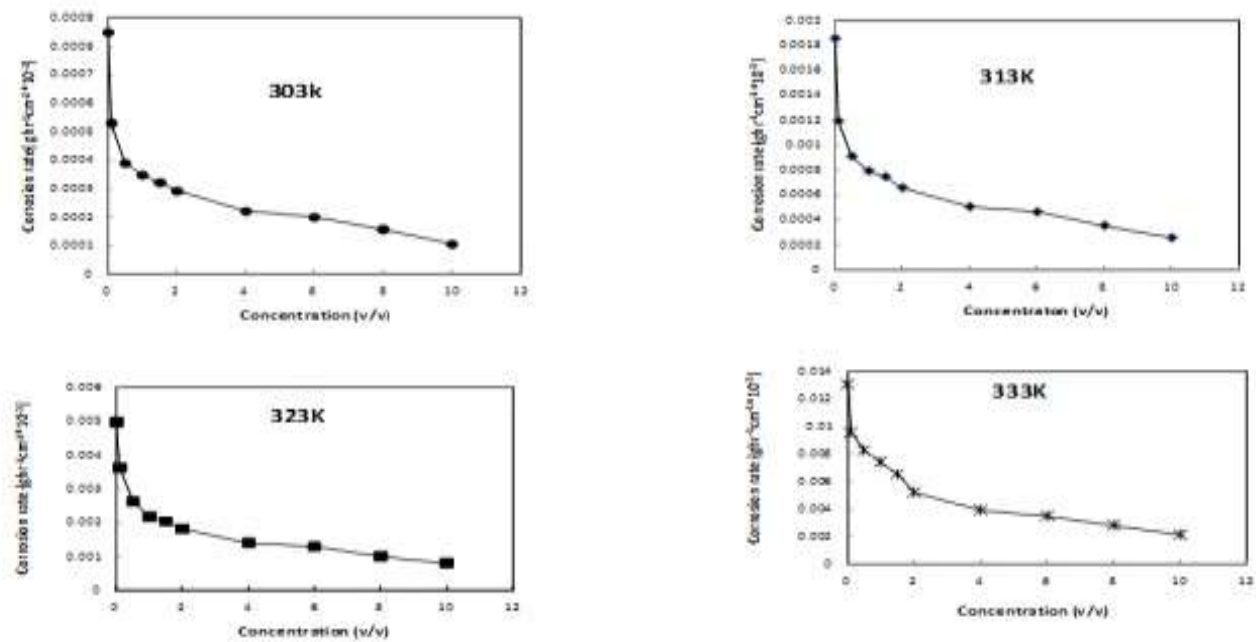

Figure1: Effect of concentration of the extract on the corrosion rate of mild steel 


\subsubsection{Effect of Concentration on Inhibition Efficiency}

As shown in Figure 2, the inhibition efficiency of the extracts on the mild steel increases with increasing concentration of the plant extracts. This is expected because as the concentration of the plant extracts increases, the fraction of the surface covered by the adsorbed molecule also increases which results into an increase in the inhibition efficiency. The inhibition efficiency increases progressively as the concentration of the extracts increases up to about $4 \%$, above which, further increase in extract concentration did not cause any significant change in the performance of the extracts. However, the inhibition efficiency decreases with increase in the temperature of the reaction medium. The maximum percentage inhibition of $88.50 \%$ was achieved $30^{\circ} \mathrm{C}$.
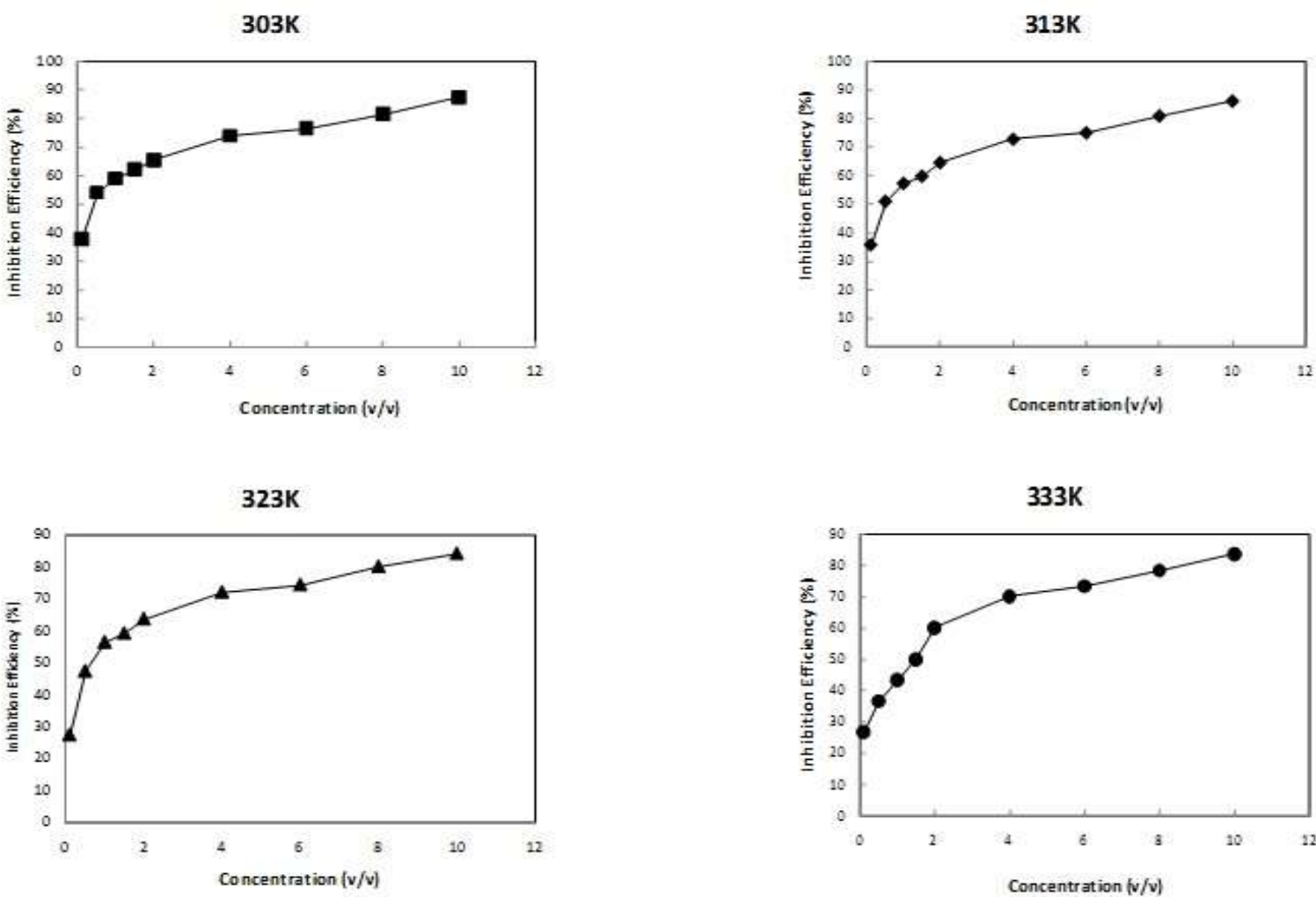

Figure 2: Effect of concentration of Musa sapientumextract on the Inhibition Efficiency of mild steel

\subsubsection{Effect of Temperature on Corrosion Rate}

The effect of temperature on the corrosion rate of mild steel in free acid and in the presence of different concentrations of the inhibitor was studied in the temperature range of $30^{\circ} \mathrm{C}$ to $60^{\circ} \mathrm{C}$. As shown in Figure 3, it was observed that the rate of corrosion of mild steel in free acid solution increases with increase in temperature. However, the corrosion rate is much decreased for the inhibited acid solution than in the free acid solution. This shows that as temperature increases, the rate of corrosion of mild steel also increases as a result of increase in the average kinetic energy of the reacting molecules. The decrease in the corrosion rate for the inhibited acid solution is as a result of the mitigating effect of the plant extract on the corrosion rate of the mild steel.

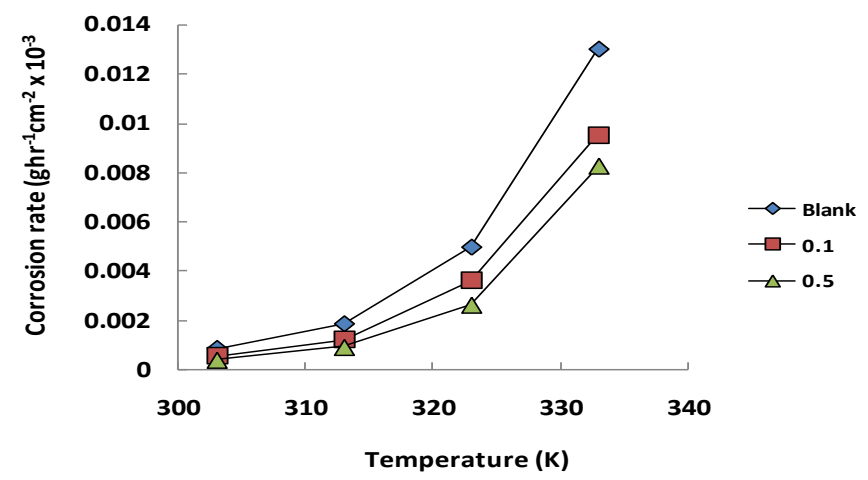

Figure 3: Effect of Temperature on corrosion rate of Musa sapientum 


\subsubsection{Effect of Temperature on Inhibition Efficiency}

The effect of increase in temperature on the inhibition efficiency of Musa sapientum extract is shown in Figure 4. It was observed that as the reaction temperature increases from $30^{\circ} \mathrm{C}$ to $60^{\circ} \mathrm{C}$, the inhibition efficiency of the Musa sapientum extract on the mild steel also decreases suggesting an increase in the corrosion rate. Previous investigators showed that the corrosion rate increases with increase in temperature [3], which results into a decrease in the inhibition efficiency, Therefore, decreasing the reaction temperature favours the inhibition efficiency of acid extracts of Musa sapientum on mild steel in hydrochloric acid.

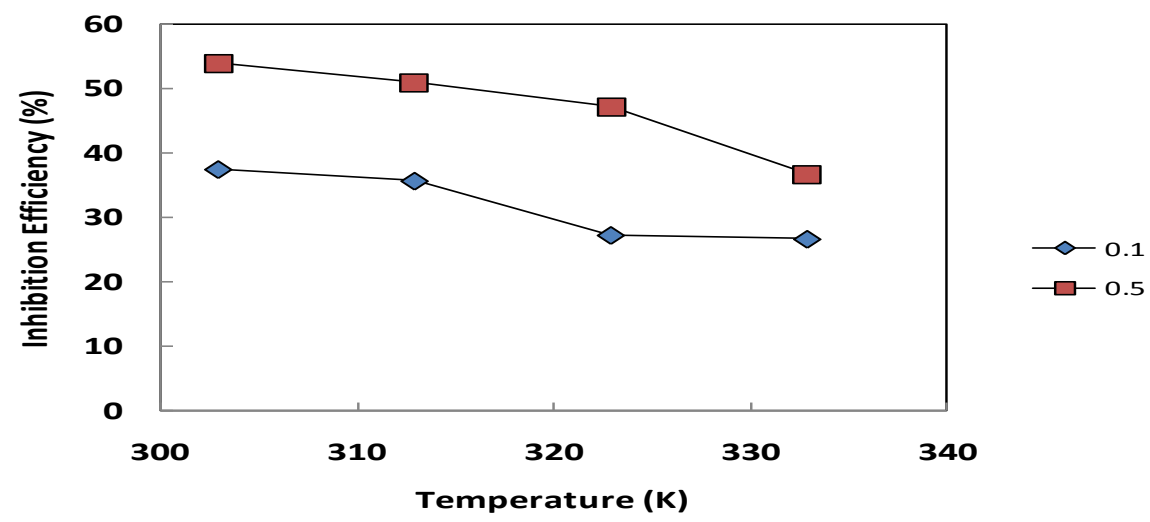

Figure 4: Effect of Temperature on the Inhibition Efficiency of Musa sapientumextract on mild steel

\subsection{Adsorption Parameters}

Adsorption isotherms are very important in determining the mechanism of organo-electrochemical reaction. The inhibition of the corrosion of mild steel in $1 \mathrm{M} \mathrm{HCl}$ medium with addition of different concentrations of the extract can be explained by the adsorption of the components of the plant extract on the metal surface. Inhibition Efficiency (\%) is directly proportional to the fraction of the surface covered by the adsorbed molecule $(\theta)$. Therefore, the adsorption isotherm describes the relationship between the coverage of interface with the adsorbed species and the concentration of species in solution. The value of the surface coverage $(\theta)$ at different concentrations of the inhibitors in $1 \mathrm{M} \mathrm{HCl}$ solution for the extract was made to fit to various adsorption isotherms. An inhibitor is found to obey Langmuir if the plot of $\log \theta / 1-\theta$ vs $\log \mathrm{C}$ or the plot of $\log C / \theta^{v s} \log C$ is linear. Similarly, for Temkin the plot of $\theta$ vs $\log C$, for BET $\log C-\log \theta$ vs $\theta^{3 / 2}$ and for Frumkin plot $\theta \mathrm{C}$ vs $\theta$ will be linear as discussed [15]. In this study, Langmuir and Temkin adsorption isotherms were found to be suitable for the experimental findings. The isotherm is described by the equation (4) as given by $[15,16]$.

$$
C_{/ \theta}=1 / K_{a d s}+\mathrm{C}
$$

Where $\mathrm{C}$ is the Inhibitor concentration, $\mathrm{K}_{\mathrm{ads}}$ is the adsorption equilibrium constant and $\theta$ is the Surface coverage.

Taking logarithm of equation 4 above yields equation (5)

$$
\log (C / \theta)=\log C-\log \mathrm{k}_{\mathrm{ads}}
$$

The plot of $\log (C / \theta)$ versus $\log C$ was linear with the intercept equal to $-\log \mathrm{K}_{\text {ads }}$ for the extract (see Fig. 5). The estimated values for $k_{\text {ads }}$ and correlation coefficient $\mathrm{R}^{2}$ for the extract at various temperatures are shown in the Table 1:

Table 1: Adsorption Equilibrum constant $\left(\mathrm{K}_{\mathrm{ads}}\right.$ at different Temperatures

\begin{tabular}{ccc}
\hline Temperature $(\mathbf{K})$ & $\mathbf{K}_{\text {ads }}$ & $\mathbf{R}^{2}$ \\
\hline 303 & 0.76296 & 0.9980 \\
313 & 0.56011 & 0.9967 \\
323 & 0.51790 & 0.9996 \\
333 & 0.46341 & 0.9996 \\
\hline
\end{tabular}


The plot of $\theta$ vs $\log \mathrm{C}$ was linear for Musa sapientum(see Fig. 6). The plots support the assertion that the mechanism of corrosion inhibition is due to the formation and maintenance of a protective film on the metal surface and that the additive covers both the anodic and cathodic sites through uniform adsorption [13]. The fit of the experimental data to these isotherms provide evidence for the role of adsorption in the observed inhibitive effect of the Musa sapientum.

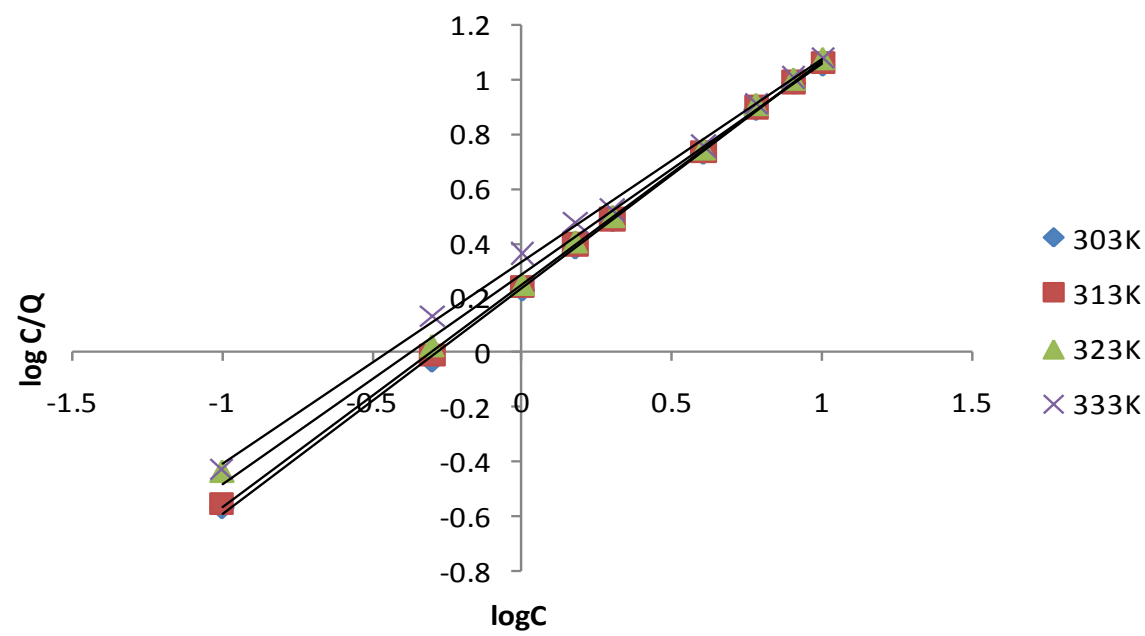

Figure 5: Langmuir isotherm for Musa sapientum

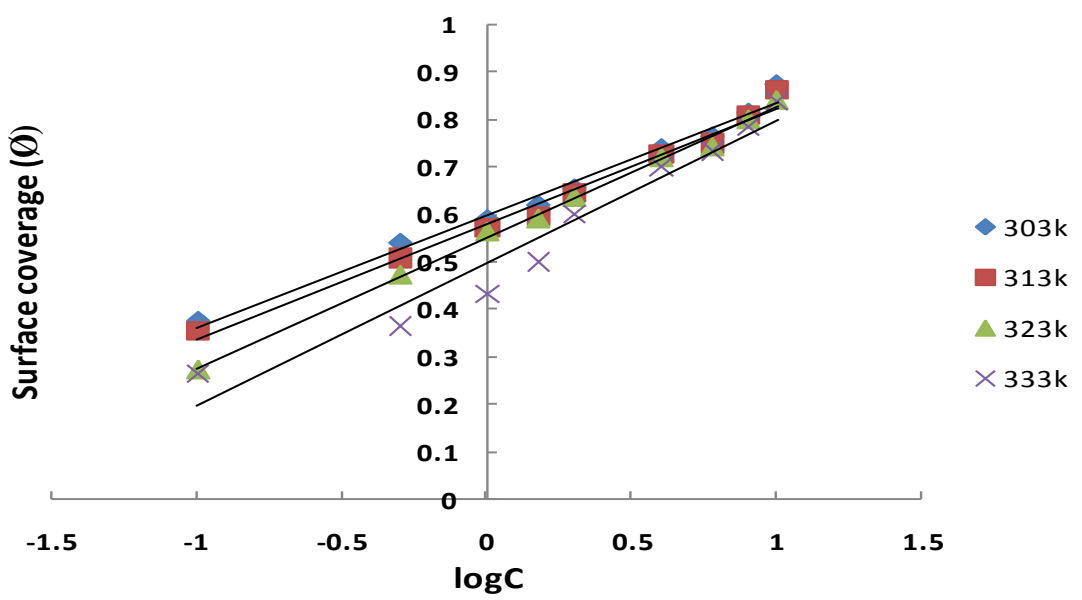

Figure 6: Temkin isotherm for Musa sapientum

\subsection{Thermodynamic Study}

\subsubsection{Activation Energy}

The adsorption of organic compounds can be described by two main types of interactions: physical adsorption and chemisorption. They are influenced by the nature of the charge of the metal, the chemical structure of the inhibitor, $\mathrm{pH}$, the type of the electrolyte and temperature [17]. Thus, in order to elucidate the inhibitive properties of the inhibitor and the temperature dependence on the corrosion rates, the apparent activation energy (Ea) for the corrosion process in the absence and presence of the inhibitor was evaluated from Arrhenius equation [11]:

$$
\text { In }\left({ }^{2} / C R_{1}=E a / R^{1}\left(T_{1}-1 / T_{2}\right)\right. \text {. }
$$

Where $C_{1}$ and $C R_{2}$ are the corrosion rates at temperature $T_{1}$ and $T_{2}$ respectively, Ea is the apparent activation energy and $\mathrm{R}$ is the molar gas constant.

The estimated values of Ea for mild steel corrosion in the presence of Musa sapientum extract in $1 \mathrm{M}$ $\mathrm{HCl}$ are listed in the Table 2. Activation energy was found to be $61.60 \mathrm{KJmol}^{-1}$ in the absence of the extract and increases to $66.72 \mathrm{KJmol}^{-1}$ in the presence of Musa sapientum extract at $0.5 \mathrm{v} / \mathrm{v}$ which shows that the adsorbed organic matter has provided a physical barrier to the change and mass transfer, leading to reduction in corrosion rate. It has been reported that when the values of $\mathrm{Ea}>80 \mathrm{~kJ} / \mathrm{mol}$ it indicates chemical adsorption whereas $\mathrm{Ea}<80$ 
$\mathrm{kJ} / \mathrm{mol}$ infers physical adsorption $[15,16]$. In the present study, a physical adsorption mechanism is proposed since the values for the $\mathrm{E}_{\mathrm{a}}$ are less than $80 \mathrm{~kJ} / \mathrm{mol}$.

As observed from Table 2, the activation energyincreased with increasing concentration of Musa sapientum and all values of $E$ a in the range of the studied concentration were higher than that of the uninhibited solution. The increase in Ea in the presence of Musa sapientumextract may be interpreted as due to physical adsorption or weak chemical bonding between the inhibitor species and the mild steel surface which resulted into decrease in the corrosion rate of the mild steel. It should be pointed out that as the concentration of the extract increases, Ea also increases which implies that the corrosion rate is decreasing. Thus, an increase in the inhibition efficiency was observed

\begin{tabular}{cc}
\hline $\begin{array}{c}\text { Table 2: } \\
\text { Concentration of Extract }(\mathbf{v} / \mathbf{v})\end{array}$ & $\mathbf{E}_{\mathbf{a}}\left(\mathbf{K J ~ m o l}^{-1}\right)$ \\
\hline Blank & Musa sapientum \\
0.1 & 61.60 \\
0.5 & 63.84 \\
1.0 & 64.22 \\
1.5 & 64.74 \\
2.0 & 66.14 \\
\hline
\end{tabular}

\subsubsection{Determination of Enthalpy and Entropy}

Thermodynamic parameters such as enthalpy $(\Delta \mathrm{H})$ and entropy $(\Delta \mathrm{S})$ of activation of corrosion process may be evaluated from the effect of temperature. The enthalpy and entropy of activation of corrosion process was calculated from the equation:

$$
\log C R / T=\log (R / n h)+\Delta S / 2.303 R-\Delta H / 2.303 R T
$$

Where ' $C R$ ' is the corrosion rate, ' $T$ ' is the absolute temperature, ' $R$ ' is the molar gas constant, ' $n$ ' is Avogadro's constant, and ' $h$ ' is the Planck's constant. A plot of $\log C R / T$ vs $1 / T$ is a straight line graph (see Fig. 7) with a slope of $(-\Delta H / 2.303 R T)$ and an intercept of $(\log (R / n h)+\Delta S / 2.303 R)$. From the slope and the intercept, $\Delta H$ and $\Delta$ Swere calculated as reported by Abiola et al. [18-19].

The results presented in Table 3 show that the enthalpy of activation values were all positive for Musa sapientum which reflects the endothermic nature of the mild steel dissolution process. Also, the entropies of activation were positive indicating that the activation complex represents association steps and that the reaction was spontaneous and feasible. These results were in excellent agreement with the previous study [17].

Table 3: Enthalpy and Entropy values of the reaction with various concentrations of the extracts

\begin{tabular}{ccc}
\hline Concentration of Extract (v/v) & $\mathbf{H}\left(\mathbf{K J} \mathbf{~ m o l}^{-1}\right)$ & $\mathbf{S}\left(\mathbf{K J} \mathbf{~ m o l}^{-1} \mathbf{K}^{-1}\right)$ \\
\hline Blank & 74.24335551 & 0.0595709 \\
0.1 & 79.24422873 & 0.0470412 \\
0.5 & 80.08579373 & 0.0467806 \\
1.0 & 82.44666551 & 0.0467806 \\
1.5 & 81.21389216 & 0.0448277 \\
2.0 & 78.14211217 & 0.0556715 \\
\hline
\end{tabular}

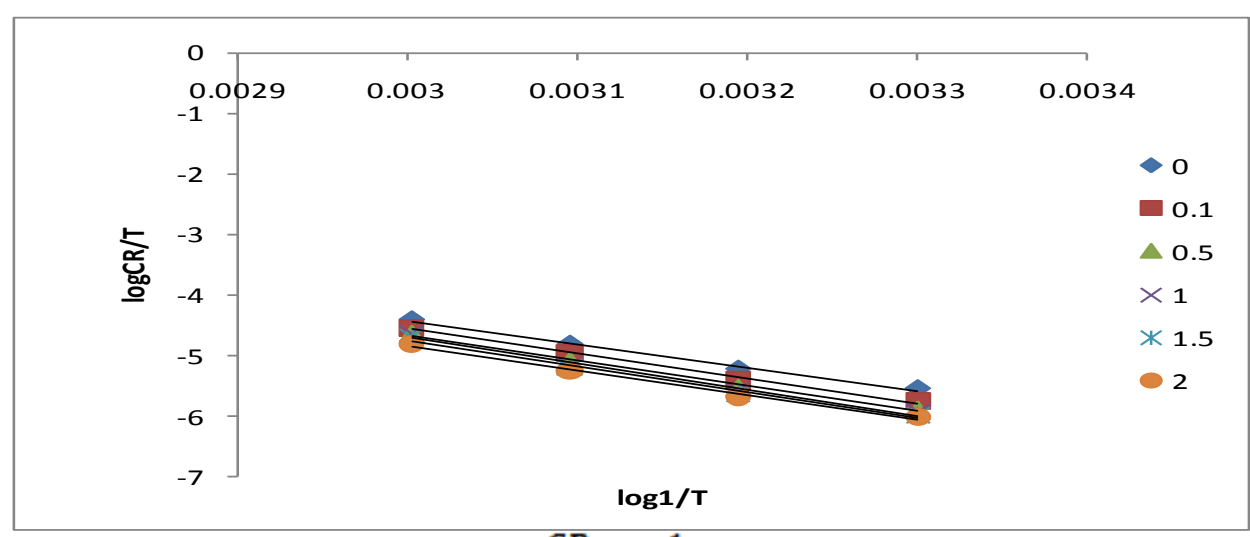

Figure 7: Plot of $\log C R / T^{\mathrm{vs}} 1 / T$ for Musa sapientum 


\subsubsection{Free Energy of Adsorption,}

The free energy of adsorption values, $\Delta \mathrm{G}^{\circ}$ ads, were obtained by using equation (8) and the values obtained are presemted in Table 4.

$$
\Delta \mathrm{G}^{\circ}{ }_{\text {ads }}=-2.303 \mathrm{RT} \log \left(55.5 \mathrm{~K}_{\mathrm{ads}}\right)
$$

Results obtained indicate that the values of $\Delta \mathrm{G}^{\circ}$ ads are negative in all cases, showing that the reaction is spontaneous [18] and that the Musa sapientum extracts are strongly adsorbed on the mild steel surface by physical adsorption. Previous investigators showed that the values of $\Delta \mathrm{G}^{\circ}$ ads $\mathrm{up}$ to $-20 \mathrm{kJmol}^{-1}$ are consistent with electrostatic interaction between charged molecules and a charged metal (which indicates physisorption), while those more negative than $-20 \mathrm{KJ} \mathrm{mol}^{-1}$ involve charge sharing or transfer from the inhibitor molecules to the metal surface to form a co-ordinate type of bond (which indicates chemisorption). This observation also supports the earlier assertion that a physical adsorption is proposed as a result of electrostatic attraction between charged metal surface and charged species in the bulk of the solution. The $\Delta \mathrm{G}$ values which are less than $10.5 \mathrm{~kJ} / \mathrm{mol}$ for various inhibitor concentrations (Table 4) revealed the decreased rate of corrosion reaction which is also substantiated by other studies $[15,18]$.

Table 4: The Free energy of Adsorptions at various Temperatures

\begin{tabular}{cc}
\hline Temperature $(\mathbf{K})$ & $-\square \mathbf{G}_{\text {ads }}^{\mathbf{0}}\left(\mathbf{K} \mathbf{J} \mathbf{J m o l}^{\mathbf{1}}\right)$ \\
\hline 303 & -9.43799 \\
313 & -8.94503 \\
323 & -9.02036 \\
333 & -8.99183 \\
\hline
\end{tabular}

\subsection{Kinetic Study}

\subsubsection{Determination of Rate Constant}

The corrosion reaction is a heterogeneous reaction which is composed of anodic and cathodic reactions at the same or different rate. It is on this basis that kinetic analysis of the data is considered necessary. In this present study, the initial weight of mild steel coupon is designated $\mathrm{W}_{\mathrm{i}}$ while the weight after time $t$ is $\mathrm{W}_{\mathrm{L}}$, hence the weight change after time $t$ is $\left(\mathrm{W}_{\mathrm{i}}-\mathrm{W}_{\mathrm{L}}\right)$. The rate constant was calculated using equation 9 as reported by the previous investigator [19].

$$
\ln \left(\mathrm{W}_{\mathrm{i}}-\mathrm{W}_{\mathrm{L}}\right)=-\mathrm{k}_{1} \mathrm{t}+\ln \mathrm{W}_{\mathrm{L}}
$$

The plots of $\ln \left(\mathrm{Wi}-\mathrm{W}_{\mathrm{L}}\right.$ ) against time (in days) at room temperature was studied which showed a linear variation and slope $\mathrm{k}_{1}$ confirms a first order reaction kinetics with respect to the corrosion of mild steel in $1 \mathrm{M} \mathrm{HCl}$ solutions in the presence of the Musa sapientum extract (Figure 8).

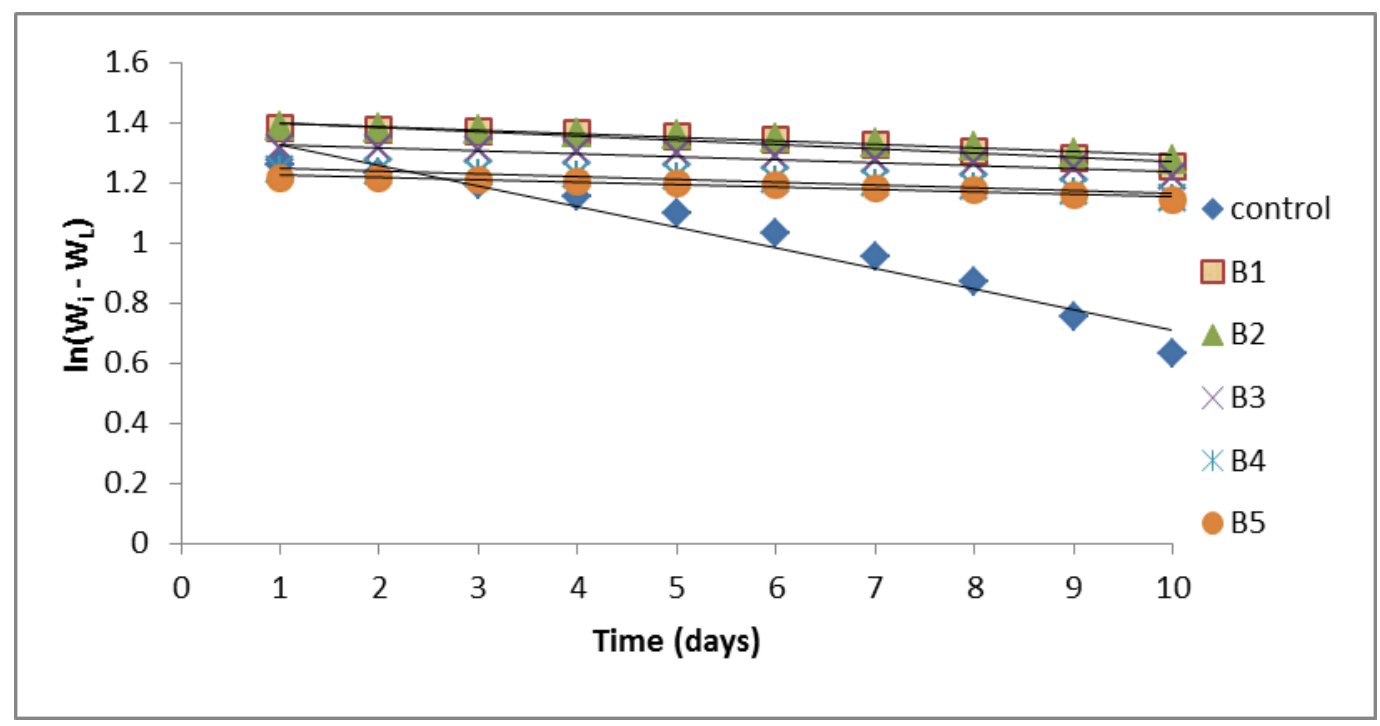

(Where B1- B5 are concentrations at $2,4,6,8$ and $10 \% \mathrm{v} / \mathrm{v}$ respectively)

Figure 8: Variation of $\ln \left(\mathrm{Wi}-\mathrm{W}_{\mathrm{L}}\right)$ with time (days) for mild steel coupons in $1 \mathrm{M} \mathrm{HCl}$ solution containing Musa sapientumat 303K. 


\subsubsection{Determination of Half Life}

The half-life $\left(\mathrm{t}_{1 / 2}\right)$ was calculated from the relation below as shown in Table 6:The increase in half-life

$$
t_{1 / 2}=0.693 / K_{1} .
$$

when the Musa sapientum extracts were added further supports the inhibition of mild steel in $1 \mathrm{M} \mathrm{HCl}$ by the additives. It should be pointed out that as the concentration of the extracts increases, the half-life also increases which corroborates the earlier assertion that as the concentration of the extracts increases, the corrosion rate decreases which results into higher inhibition efficiency. Hence, more protection of the metals by the Musa sapientum extracts would be established. Based on the value of the activation energy which is in the range of $61 \mathrm{~kJ} / \mathrm{molto} 67 \mathrm{~kJ} / \mathrm{mol}$, the additive is physically adsorbed on the metal coupons. Therefore, it is likely that a multilayer protective coverage on the entire mild steel surface was obtained[19].

Table 5: Half life parameters at various concentrations

\begin{tabular}{ccc}
\hline Concentration of Extract $(\mathbf{v} / \mathbf{v})$ & Rate Constant $\left(\times \mathbf{~ 1 0}^{-\mathbf{3}} \mathbf{d a y}^{-\mathbf{1}}\right)$ & Half life $\left(\times \mathbf{~ 1 0}^{\mathbf{3}} \mathbf{\text { day}}\right)$ \\
\hline Blank & 0.06818 & 10.16397 \\
2.0 & 0.01398 & 49.5753 \\
4.0 & 0.01175 & 58.97455 \\
6.0 & 0.01005 & 68.93602 \\
8.0 & 0.00968 & 71.60756 \\
10.0 & 0.00798 & 90.25879 \\
\hline
\end{tabular}

\subsection{Phytochemical Constituents}

Preliminary investigations of phytochemical constituents of the Musa sapientum extract was reported in Table 6.Inspection of the chemical structures of these phytochemical constituents reveal that these compounds are easily hydrolysable and the compounds can be adsorbed on the metal surface via the lone pair of electrons present on their oxygen atoms (i.e. they contain multifunctional group) which make a barrier for charge and mass transfer leading to decrease the interaction of the metal with the corrosive environment. As a result, the corrosion rate of the metal was decreased. The formation of film layer essentially blocks the discharge of $\mathrm{H}^{+}$and dissolution of the metal ions. Due to electrostatic interaction, the protonated constituent's molecules are adsorbed (physisorption) and high inhibition is expected.

Table 6: The phytochemical constituents of Musa sapientum extract

\begin{tabular}{lc}
\hline Phytochemicals & Musa sapientum \\
\hline Alkaloid & + \\
Saponin & + \\
Tannin & + \\
Flavonoid & - \\
Anthraquinone & + \\
Terpenoid & - \\
Syenoid & - \\
Phlobatannin & + \\
Legal Yeast & + \\
Keller Kiliani & + \\
Salkowski & + \\
Lieberman & - \\
\hline
\end{tabular}

\section{Conclusion}

1. The acid extract of Musa sapientum acts as good and efficient inhibitor for the corrosion of mild steel in hydrochloric acid medium.

2. Inhibition efficiency increases with inhibitor concentration and maximum inhibition efficiency for the extract was found to be $87.50 \%$ at the optimum concentration of $10 \% \mathrm{v} / \mathrm{v}$ at $30^{\circ} \mathrm{C}$.

3. The adsorption of different concentrations of the plant extract on the surface of the mild steel in $1 \mathrm{M} \mathrm{HCl}$ acid followed both Langmuir and Temkin adsorption isotherm.

4. The negative sign of the Free Energy of adsorption indicates that the adsorption of the inhibitors on the mild steel surface was a spontaneous process and was found to be physiosorption.

5. The positive values of enthalpy of adsorption $(\Delta \mathrm{H})$ suggest that the chemical reaction involved in the adsorption of the inhibitors on the metal surface is an endothermic process, hence increase in the reaction temperature of the medium will decrease the inhibition efficiency. 
6. The positive values of entropy of adsorption indicate that the reaction was spontaneous and feasible.

7. Activation energy Ea was found to be $61.60 \mathrm{KJmol}^{-1}$ for $1 \mathrm{M} \mathrm{HCl}$ and increases to $66.72 \mathrm{KJmol}^{-1}$ in the presence of Musa sapientum extract which shows that the adsorbed organic matter has provided a physical barrier to change and mass transfer, leading to reduction in the rate of corrosion.

8. The mechanism of the physical adsorption was proposed and a first order type of reaction is obtained from the kinetic treatment of the data.

\section{References}

[1]. A. H. Ostovari, S. M. Peikari, M. Shadizadeh, S. R. Hashemi, Corrosion inhibition of mild steel in $1 \mathrm{M}$ HCl solution by henna extracts: A comparative study of the inhibition of henna and its constituents (Lawsone, Gallic acid, \{alpha\}-d-Glucose and Tannic acid). Corrosion Science, 51 (9), 2009, 1935-1949

[2] H. Ashassi-Sorkhabi, D. Seifzadeh, and M. G. Hosseini, EN, EIS and polarization studies to evaluate the inhibition effect of 3Hphenothiazin-3-one, 7-dimethylamin on mild steel corrosion in 1M HCl solution, Corrosion Science, 50 (12), 2008, 3363-3370.

[3] M.A. Quraishi, D. K. Yadav, and I. Ahamad, Green Approach to corrosion inhibition by black pepper extract in hydrochloric acid solution. Open Corrosion Journal, 2, 2009, 56-60.

[4] R. Saratha and V.G. Vasudha, Inhibition of mild steel corrosion in $1 \mathrm{~N}_{2} \mathrm{SO}_{4}$ medium by acid extract of Nyctanthesarbortristis leaves. E-Journal of Chemistry, 6(4), 2009, 1003-1008.

[5] A. Rajendran, Isolation, characterization, pharmacological and corrosion inhibition studies of flavonoids obtained from Nerium oleander andTecomastans." International Journal of PharmTech Research, 3 (2), 2011, 1005-1013.

[6] R. Saratha and V.G. Vasudha, EmblicaOfficinalis(Indian Gooseberry) leaves extract as corrosion inhibitor for mild steel in 1N HCl medium. E-Journal of Chemistry, 7(3), 2010, 677-684.

[7] O. O. Adeyemi and O. O. Olubomehin. Investigations of Anthocleistadjalonesisstem bark extract of corrosion inhibitor for aluminium. Pacific Journal of Science and Technology, 11 (2), 2010, $455 \square$ 462. (Fall)

[8] O. O. Ajayi, O.A. Omotosho, K.O Ajanaku and B.O. Olawore, Failure evaluation of aluminium alloy in 2M Hydrochloric acid in the presence of Cola acuminata. Environ. Res. Journal, 5(4), 2011, 163-169.

[9] S. Ambrish and M.A. Quraishi, Pipali(Piper longum) and Brahmi(Bacopamonneiri) extracts as green corrosion inhibitor for aluminium in $\mathrm{NaOH}$ solution. Journal of Chemical and Pharmaceutical Research, 4(1), 2012, $322 \square 325$.

[10] L. E. Umoru, I. A. Fawehinmi and A.Y Fasasi, Investigation of the Inhibitive Influence of Theobroma cacao and Cola acuminate Leaves Extracts on the corrosion of a Mild Steel in Sea Water." Journal of Applied Sciences Research, 2(4), 2006, $200-204$.

[11] P. D. Rani and S. Selvaraj. Inhibitive and adsorption properties of Punicagranatumextracts on brass in acid media. Journal of Phytology, 2(11), 2010, 58-64.

[12] M. H. Hussin and M. J. Kassim, Electrochemical studies of mild steel corrosion inhibition in aqueous solution by Uncariagambirextract. Journal of Physical Science, 21(1), 2010, 1-13.

[13] J. T. Wabanne and V. Okafor, Inhibition of the corrosion of mild steel in acidic medium by Vernoniaamygdalina: Adsorption and Thermodynamics Study. Journal of Emerging Trends in Engineering and Applied Sciences, 2 (4), 2001, 619-625.

[14] E. U. Onyeka and I. O. Nwabekwe, Phytochemical profile of some green leafy vegetable in S.E. Nigeria. Nigerian Food Journal, 25 (1), 2007, $67-76$.

[15] M. Ismail, A. S. Abdulrahman and M. S. Hussain, Solid waste as environmental benign corrosion inhibitors in acid medium.International Journal of Engineering Science and Technology, 3 (2), 2011, 1742-1748.

[16] P. R. Vijayalakshmi, R. Rajalakshmi and S. Subhashini, Corrosion inhibition of aqueous extract of Cocosnucifera - coconut palm petiole extract from destructive distillation for the corrosion of mild steel in acidic medium". PortugaliaeElectrochimicaActa, 29(1),2011, 9-21

[17] W. J. Blaedel and V.W. Meloche, "Elementary Quantitative Analysis; Theory and Practice, Second Edition, Harper \& Row, Publishers, Incorporated, 49 East $33^{\text {rd }}$ Street, New York 16, New York. 1963, 684-698.

[18] O. K. Abiola, N. C. Oforka, E. E. Ebenso, and N. M. Nwinuka, Eco-friendly corrosion inhibitors: inhibitive action of delonixregra extract for the corrosion of aluminum in acidic medium, Anti-corrosion Methods \& Materials. 54, 2007, $219-224$.

[19] A. O. James, N. C., Oforka and O. K. Abiola, Inhibition of Aluminium (3SR) corrosion in hydrochloric acid by pyridoxol hydrochloride. Bulletin of Electrochemistry22, 2006, 111-116. 